\title{
STUDY INFLUENCE OF LAND COVER CHANGE IN WETLAND AND VEGETATION ON LAND SURFACE TEMPERATURE
}

\author{
Ricky Anak Kemarau*, Oliver Valentine Eboy \\ Faculty of Social Science and Humanities, University of Malaysia Sabah, 88400, Sabah, Malaysia.
}

\author{
Date received: 04/01/2021 Date accepted: 02/09/2021 \\ *Corresponding author's email: ricky.geo2005@ gmail.com \\ DOI: $10.33736 /$ jcest.3970.2021
}

\begin{abstract}
Wetlands are a vital component of land cover in reducing impacts caused by urban heat effects and climate change. Remote sensing technology provides historical data that can study the impact of development on the environment and local climate. The studies of wetland in reducing Land Surface Temperature (LST) in a tropical climate are still lacking. The objective of the study is to examine the influence of land cover change wetland and vegetation on land surface temperature between the years 1988 and 2019. First of all, step, pre-processing, namely geometric correction, atmosphere correction, and radiometric correction, were performed before retrieval of the LST dataset from thermal band Landsat 5 and 8. Then, Iso Cluster, unsupervised was chosen to produce the land cover map for 1988 and 2019. Geographical Information System (GIS) technology was utilized to determine changes to land cover and LST change between the years 1988 and 2019. With GIS technology, a study of the impact of wetland deforestation on local temperatures at a local scale was carried out. Next to that, correlations between LST and the wetland were analyzed. The results indicated the different land cover between the years 1988 and 2019. The areas of land cover for wetland and vegetation decrease and while area of urban increased. The land cover changed the influences of LST significantly in the study area. The LST increased with the decreasing in areas wetland areas for every 5-kilometer square $\left(\mathrm{km}^{2}\right)$ wetland lost an increase in 1-degree Celsius of LS was estimated. The size of wetland influence on LST was significant. Wetland and vegetation function in reducing the urban heat island effect was vital in providing a comfortable environment to the Kuching population and indirectly reduce the demand for power energy.
\end{abstract}

Copyright $(2021$ UNIMAS Publisher. This is an open access article distributed under the Creative Commons Attribution-NonCommercial-ShareAlike 4.0 International License which permits unrestricted use, distribution, and reproduction in any medium, provided the original work is properly cited.

Keywords: LST, Land cover, Surface urban heat island, Remote sensing and GIS

\subsection{INTRODUCTION}

Wetlands are well-known as the kidneys of the earth. The total area of the global wetlands is found more than 12.8 million $\mathrm{km}^{2}$ [1]. Wetlands are the significant ecosystems in the world, along with forests and oceans [1]. Wetlands contain high biodiversity and plentiful ecological roles, namely source, guideline, sustenance, and cultural functions [2]. The remote sensing technique is widely used for monitoring wetlands and their spatial distribution and temporal [3 - 5]. However, thermal infrared data are less often used. The application of thermal infrared remote sensing such as Landsat can understand the spatial distribution of land surface temperature (LST), evapotranspiration in the groundwater-dependent ecosystem. The LST-based evapotranspiration estimation is valuable in the practical application of water management [6]. Accordingly [7] LST variations were discovered, not a relationship with wetland change. However, many had studied their wetland changes had an impact on climate at large or mesoscale $[8-12,16]$ and small scale $[13,4,5]$. Wetlands are vital to land cover to determine local climate through a cold, humid effect $[4,6,12,15]$. The character of different albedo, heat, capacity, roughness, and energy exchange $[1,13,14,16]$. Wetlands reduced the LST and rose humidity under a condition of intense radiation and evapotranspiration [7]. Most studies, as mentioned above, concentered on temperate. Studies impact of the area on the wetland to LST at tropical climate lacking in the central literature review. There is a great deal of work to be done in this area on wetland and LST. During the past 31 years, Kuching had undergone rapid development. It is necessary to study wetland's effect on the local climate in this region to provide a strong foundation and knowledge for a future study on the impact of wetland change on the local climate. In this study, thermal band Landsat was applied for the years 1988 and 2019. The analyses of change detection between 1988 and 2019 were carried out to study the impact of deforestation of wetland and vegetation at the study area also examined the LST statistics between the years 1988 and 2019. The finding can enhance knowledge of environmental and climate 
effects from wetland changes, while at the same time, allowing meaningfully a quantitative understanding of wetlands' ecological functions.

\subsection{MATERIALS AND METHODS}

\subsection{Study Area}

Kuching is located at Borneo Island, which is the capital city of the state of Sarawak, Malaysia (Figure 1). The study covered Kuching North Hall and Council of the City of Kuching South urban areas, vegetation, and wetland with a total area of $601 \mathrm{~km}^{2}$. History of the region recorded that that civilization began near Sungai Sarawak. Most development in Kuching city happens surrounding Sungai Sarawak. The region climate is a tropical climate with annual precipitation of 4200 millimeters [17]. The average temperature ranges from $19{ }^{\circ} \mathrm{C}$ to $36{ }^{\circ} \mathrm{C}$ [17]). The Northeast Monsoon occurs in September until March and the Southeast Monsoon from May until August. The Northeast Monsoon is significant with the wet season in Kuching and the Southeast Monsoon is dry. In 2018, the Kuching population was 570, 407 [18]. The literature review suggested a selected study area with a small-medium city with a population below 2 million [19]. This is the primary motivation of the author to choose Kuching as there is a study area.

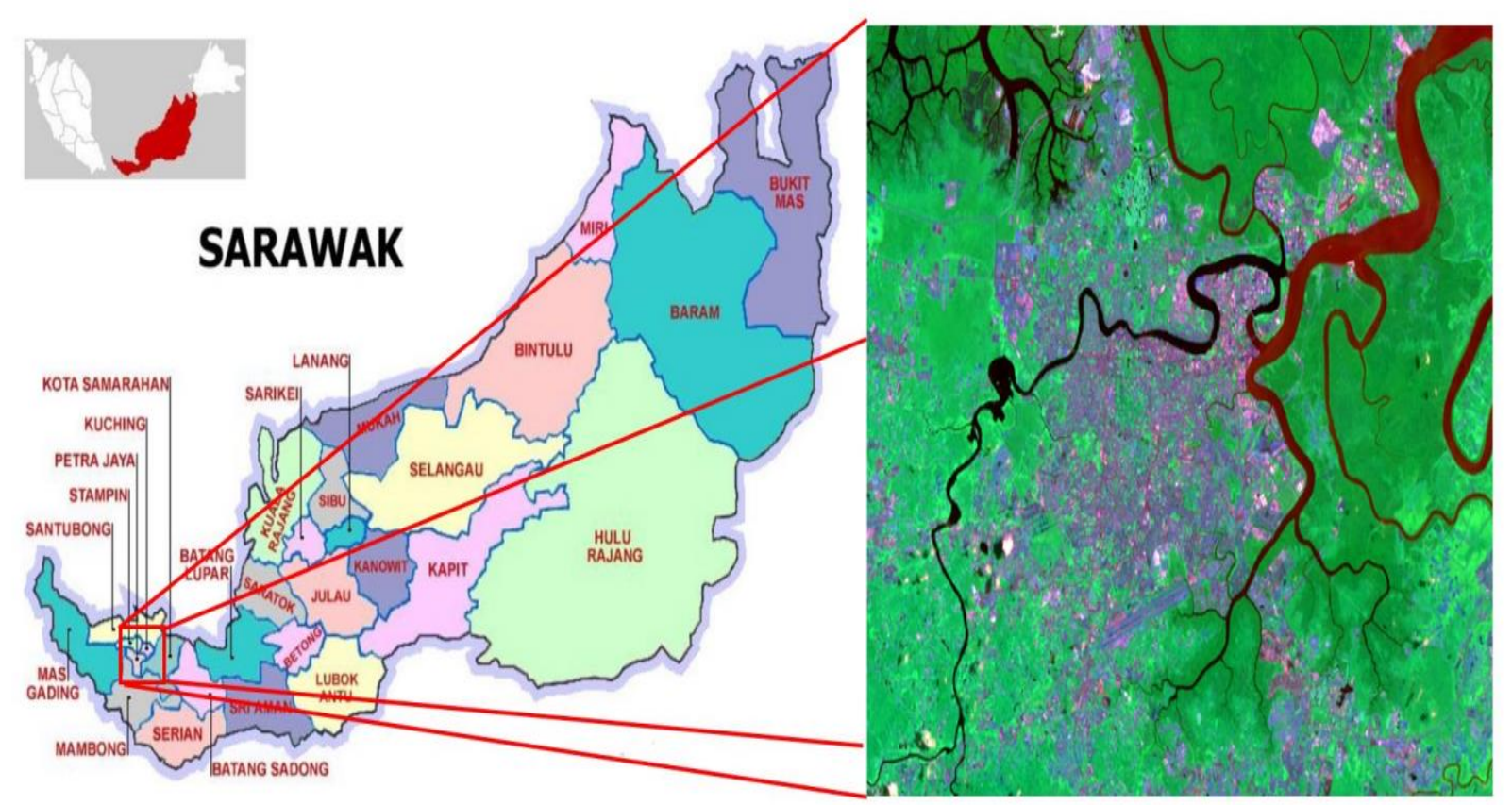

Figure 1 Location of the study area. Source: Authors

\subsection{Dataset}

This study uses two dataset data satellites of remote sensing namely Landsat 5 and Landsat 8 . Table 1 shows the information of the dataset applied in this study to the achieved objective of the study.

Table 1 Information of dataset

\begin{tabular}{|c|c|c|c|}
\hline Sensor & Thermal Band & Resolution (Meter) & Data Acquisition \\
\hline Landsat 5 Thematic Mapper (TM) & Band 6 & 100 & 25 May 1988 \\
\hline $\begin{array}{c}\text { Landsat } 8 \text { Operational Land Imager (OLI) and } \\
\text { Thermal Infrared Sensor (TIRS) }\end{array}$ & Band 10 & 120 & 15 May 2019 \\
\hline
\end{tabular}


The band 6 Landsat 5 TM and band 10 of Landsat 8 OLI TIRS were utilized in this study (Table 1).

\subsection{Data Pre-Processing and Analysis}

Pre-processing such geometric correction is required to study the change between the two-imagery data set. After that, atmosphere correction and radiometric correction are required before retrieval of LST from the thermal band (Figure 2).

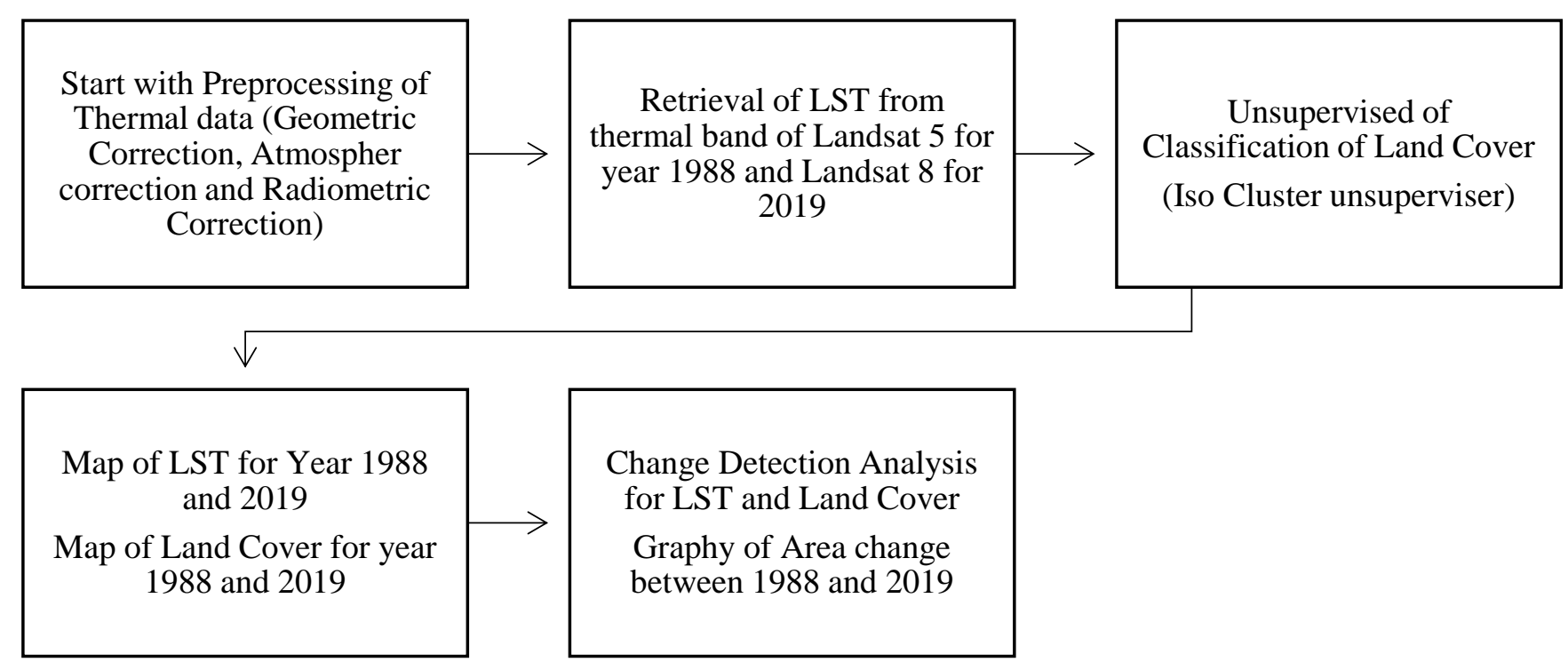

Figure 2 Flow methodology. Source: Authors

The step of retrieval of land surface temperature at Landsat 5 and Land 8 was applied based on the step-in paper [20]. After the LST map and land cover for 1988 and 2019 were created. The calculation for each land cover area was carried out. Next, this study utilized the analysis tool in ArcGIS that is Change Detection analysis to identify areas that had changed between 1988 and 2019. Correlation between LST and areas of wetland was conducted to determine the relationship between LST and total areas wetland which disappeared between 1988 and 2019.

\subsection{RESULTS AND DISCUSSION}

In the year 1988 area covered by mangroves was highest at $240.94 \mathrm{~km}^{2}$. The second highest was vegetation land cover with $231.37 \mathrm{~km}^{2}$ followed by the third urban area with $77.16 \mathrm{~km}^{2}$, and the least was water bodies with 53 $\mathrm{km}^{2}$. The trend of highest for the year 2019 was similar to 1988 with mangrove of $199.70 \mathrm{~km}^{2}$, followed by cover vegetation with $181.58 \mathrm{~km}^{2}$, third urban area with $165.86 \mathrm{~km}^{2}$, and the least water bodies with $50.69 \mathrm{~km}^{2}$. 


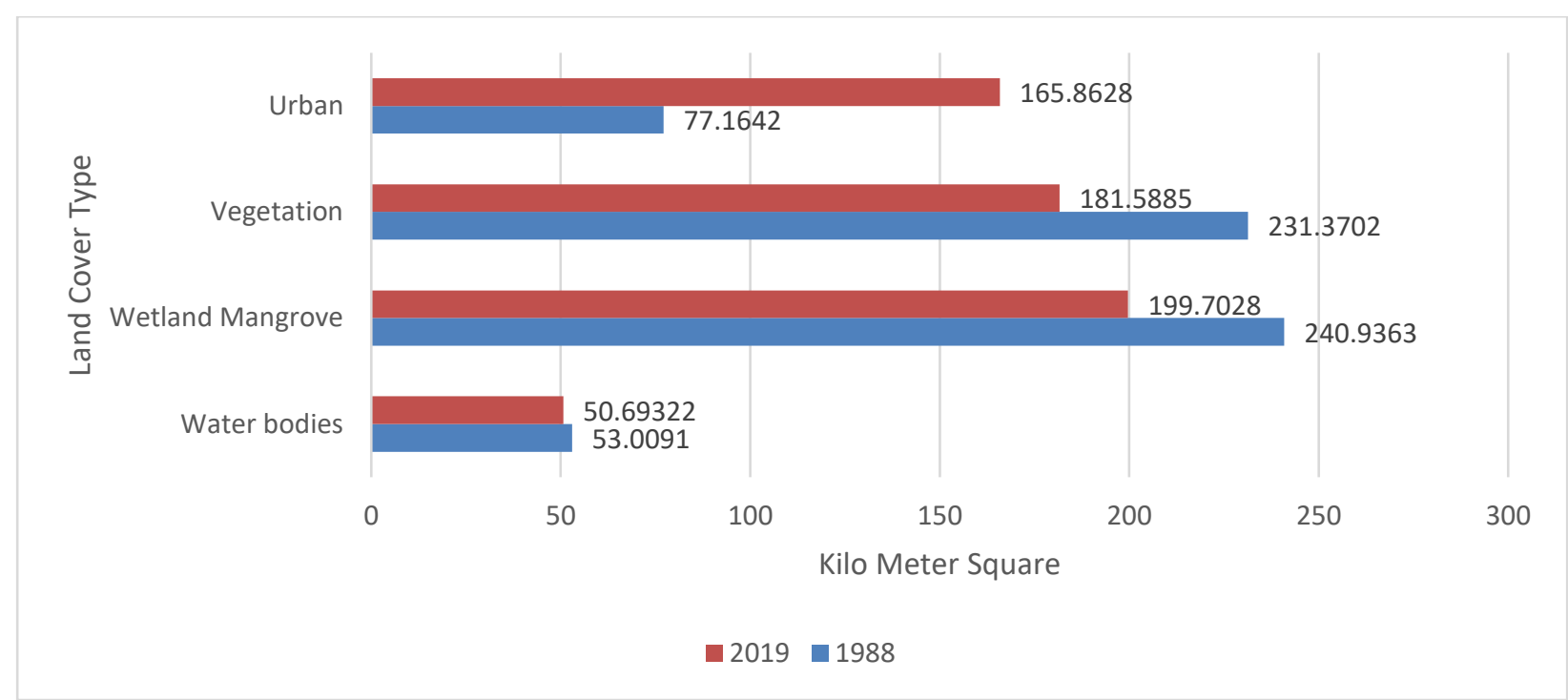

Figure 3 Comparing land cover areas in kilometer square for years 1988 and 2019.

Source: Authors.

Figure 4 shows the land cover maps for 1988 and 2019. The green area represents the vegetation in the area, the white color for the urban area, the purple color for the wetland area, and the blue area for the water body. Many changes took place between 1988 and 2019. The municipality spread from the city center to the suburbs. Many areas changed from vegetation cover in 1988 to urban areas in 2019. In addition, many wetland areas were also redeemed for development such as port areas and industrial areas as well as settlements. An in-depth explanation is discussed using Figure 5.
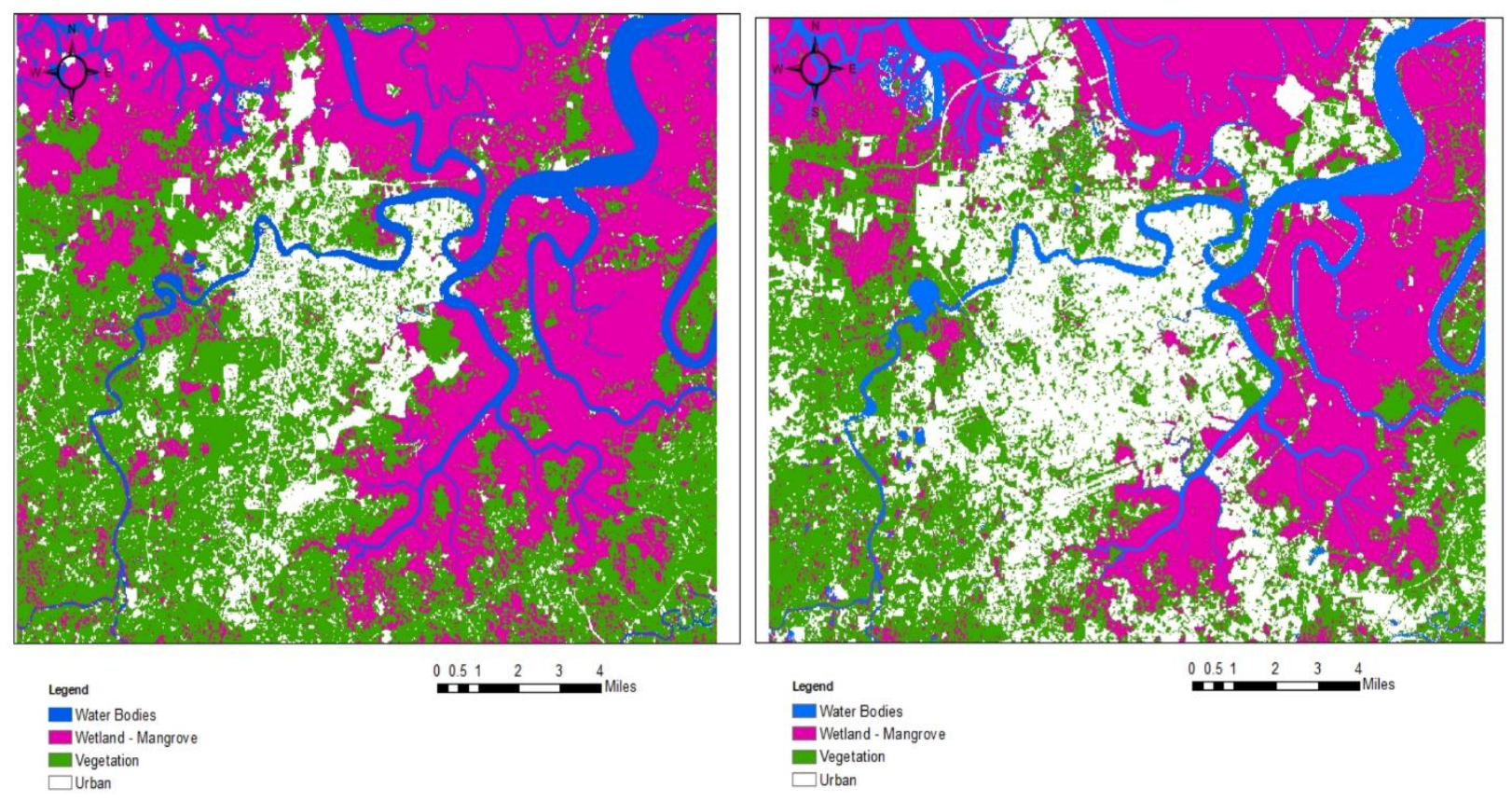

Figure 4 Land cover map of the year 1988 (Left) and Land cover map of the year 2019 (right). Source: Authors

The most significant change in land cover for the years 1988 and 2019 was the cover urban with an increase of $88.69 \mathrm{~km}^{2}$. The urbanization replaced mangrove wetland at the areas of Sama Jaya Free Industrial Zone, Pending Industrial Estate, Demak Laut Industrial Phase 1, 2, and 3. Water bodies were changes to areas build up, namely at Sama Jaya Port and Kuching Port. The next transformation was from vegetation to build-up areas for settlements 
at Tabuan Height, Kota Sentosa, Tabuan Desa, Petra Jaya, and Kampung Rampangi. The second biggest land cover change was vegetation that decreases from $49.78 \mathrm{~km}^{2}$ and followed by mangrove wetland that decreased by $41.23 \mathrm{~km}^{2}$ and lastly water bodies that decreased by $2.31 \mathrm{~km}^{2}$ (Figure 5 ).

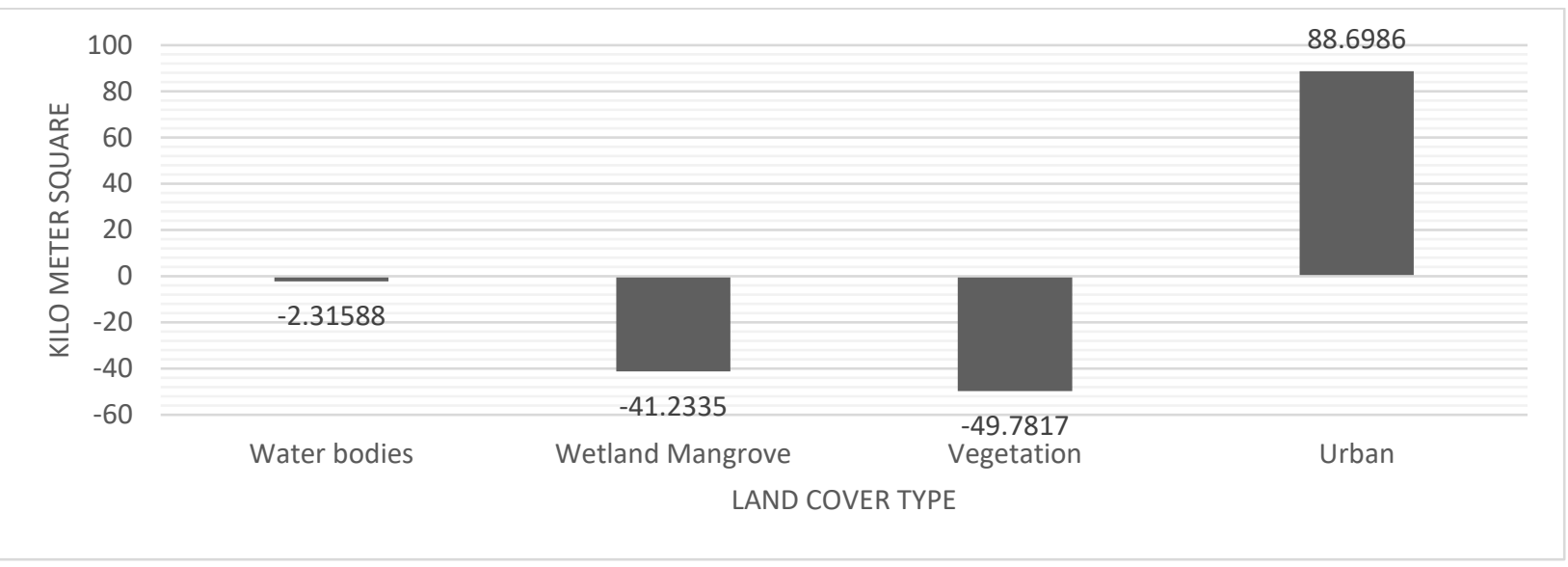

Figure 5 The land cover areas change between the years 1988 and 2019 in kilometer square.

Source: Authors

Figure 6 shows the map of LST for the years 1988 and 2019. The maps show the increase of the Surface Urban Heat Island (SUHI) effect patterns from 1988 and 2019. The SUHI patterns increased from the center of the city to the suburban area. The increase in SUHI significantly increased the LST statistics as mentioned in table 2 . The min of LST in 1988 with $18.83{ }^{\circ} \mathrm{C}$ increased to $22.24{ }^{\circ} \mathrm{C}$, and followed by the max of LST $28.76{ }^{\circ} \mathrm{C}$ in 1988 rose to $36.06{ }^{\circ} \mathrm{C}$ in 2019 . The data mean of LST also increased from $23.00{ }^{\circ} \mathrm{C}$ to $26.64{ }^{\circ} \mathrm{C}$. The increases in data statistics were because of influences growing the SUHI in the study area. The transformation from vegetation cover to buildup area causes a significant rise in LST in the surrounding study area. The data were captured both in May, which was not significantly influenced by the monsoon season.
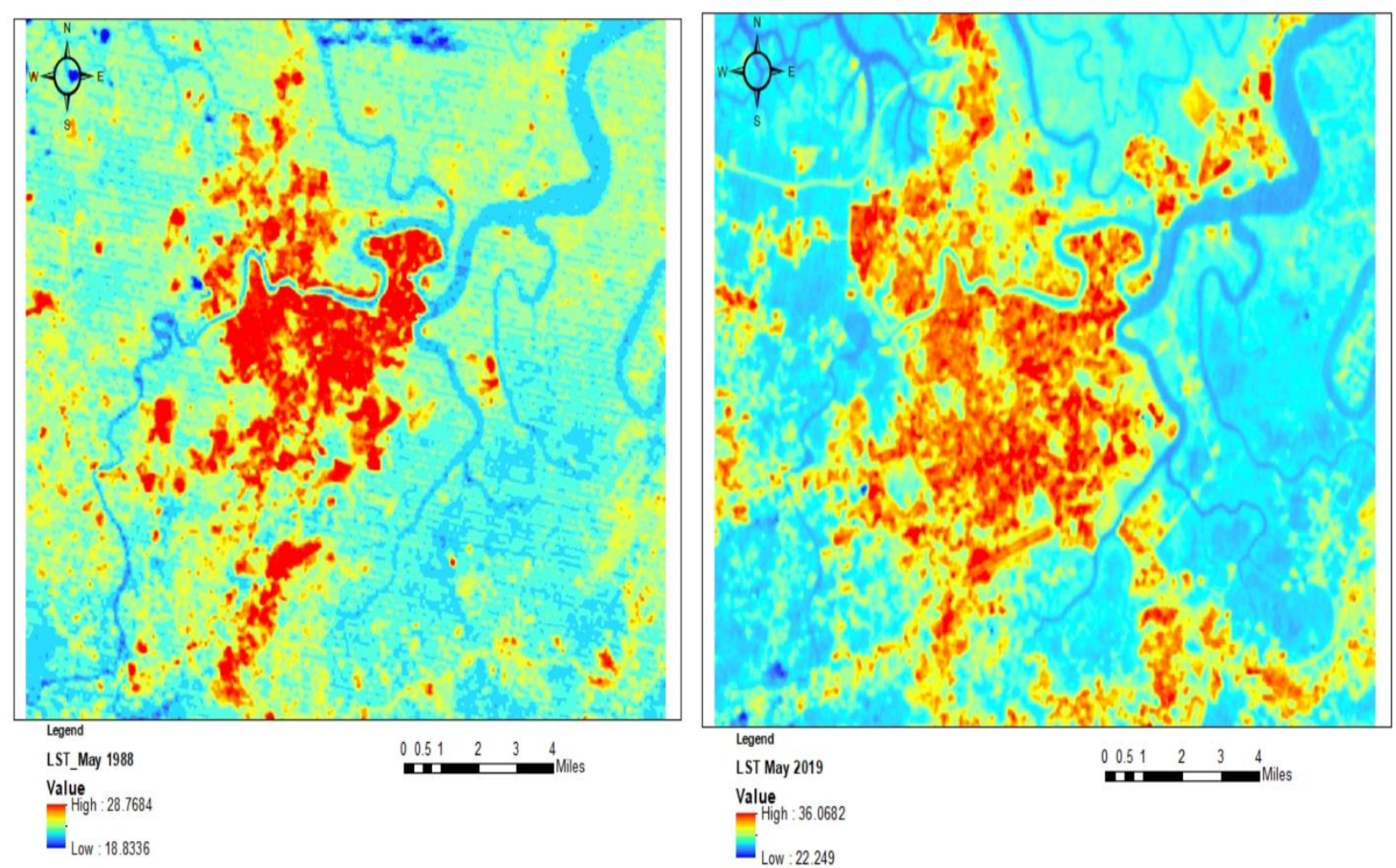

Figure 6 LST map of the year 1988 (Left) and LST map of the year 2019 (right).

Source: Authors 
Table 2 shows the LST statistical data for 1988 and 2019. Overall, the LST values recorded for 1988 are 28.76 and 36.06 degrees Celsius for 2019. The lowest temperature values for 1988 are 19.83 degrees Celsius and 22.24 degrees Celsius for 2019. The overall temperature throughout the Kuching area in 1988 was 23 degrees Celsius and 26.64 for 2019.

Table 2 LST in the study area for the years 1988 and 2019

\begin{tabular}{ccc}
\hline Data statistics & $\mathbf{1 9 8 8}$ & $\mathbf{2 0 1 9}$ \\
& $\mathbf{L S T}\left({ }^{\circ} \mathbf{C}\right)$ & $\mathbf{L S T}\left({ }^{\circ} \mathbf{C}\right)$ \\
\hline Minimum & 18.83 & 22.24 \\
Maximum & 28.76 & 36.06 \\
Mean & 23.00 & 26.64 \\
\hline
\end{tabular}

Source: Authors

Table 3 shows the mean of LST at every land cover type in the study area. The urban areas value highest had the highest mean $26.83{ }^{\circ} \mathrm{C}$ and $33.24{ }^{\circ} \mathrm{C}$ for the year 1988 and 2019 , followed by means of LST at vegetation covers $22.54{ }^{\circ} \mathrm{C}$ for the year 1988 , and respectively by values $26.78{ }^{\circ} \mathrm{C}$ for the year 2019 . The mangrove wetland for a mean value of $22.40{ }^{\circ} \mathrm{C}$ and $26.20^{\circ} \mathrm{C}$ increased the two years. The lowest mean was found at water bodies with $21.20{ }^{\circ} \mathrm{C}$ for the year 1988 and $25.93{ }^{\circ} \mathrm{C}$ for the year 2019 . The transformation from vegetation cover to build-up building areas had caused the surface properties to be more absorption of solar radiation, reduce convective cooling and lower water evaporation rates. As result, the LST at urban areas was found to be higher than vegetation and water bodies $[15,16]$.

Table 3 LST According to land cover type for the years 1988 and 2019

\begin{tabular}{ccc}
\hline Data statistics & $\mathbf{1 9 8 8}$ & $\mathbf{2 0 1 9}$ \\
& LST $\left({ }^{\circ} \mathbf{C}\right)$ & LST $\left({ }^{\circ} \mathbf{C}\right)$ \\
\hline Mean at Urban & 26.83 & 33.24 \\
Mean at Vegetation covers & 22.54 & 26.78 \\
Mean at Water bodies & 21.20 & 25.93 \\
Mean at Mangrove Wetlands & 22.40 & 26.20 \\
\hline
\end{tabular}

Source: Authors

The square white in figure 7 the year 1988 was wetland, and vegetation converts to settlement at Tabuan Baru, Riveria, and kampung Stutong. The red square (Figure 7) was indicated at Sama Jaya Free Zone Industrial, Muara Tabuan Light Industrial park, and Pending Industrial Estate. The mangrove wetland had been destroyed and replaced with build-up areas such as industrial areas and Ports. The green square was indicated at Demak Industrial Park Phase 1, 2, and 3. At here, it pointed to of Power Plant Sejingkat and settlement of Senari, Sejingkat, and Muara Tebas. The mentioned locations had the most significant change in this area, which previously in 1988, these place contained were vegetation and mangrove wetland. The black square (Figure 7) was indicates relocated to Kampung Semerah Padi Matang, Petra Jaya, and Kampung Rampangi (settlement). Most of the land covers in the area were vegetation, and wetland in 1988 was transformed into a settlement. The change of land cover from vegetation and wetland to urban/built-up significantly increases the LST. 

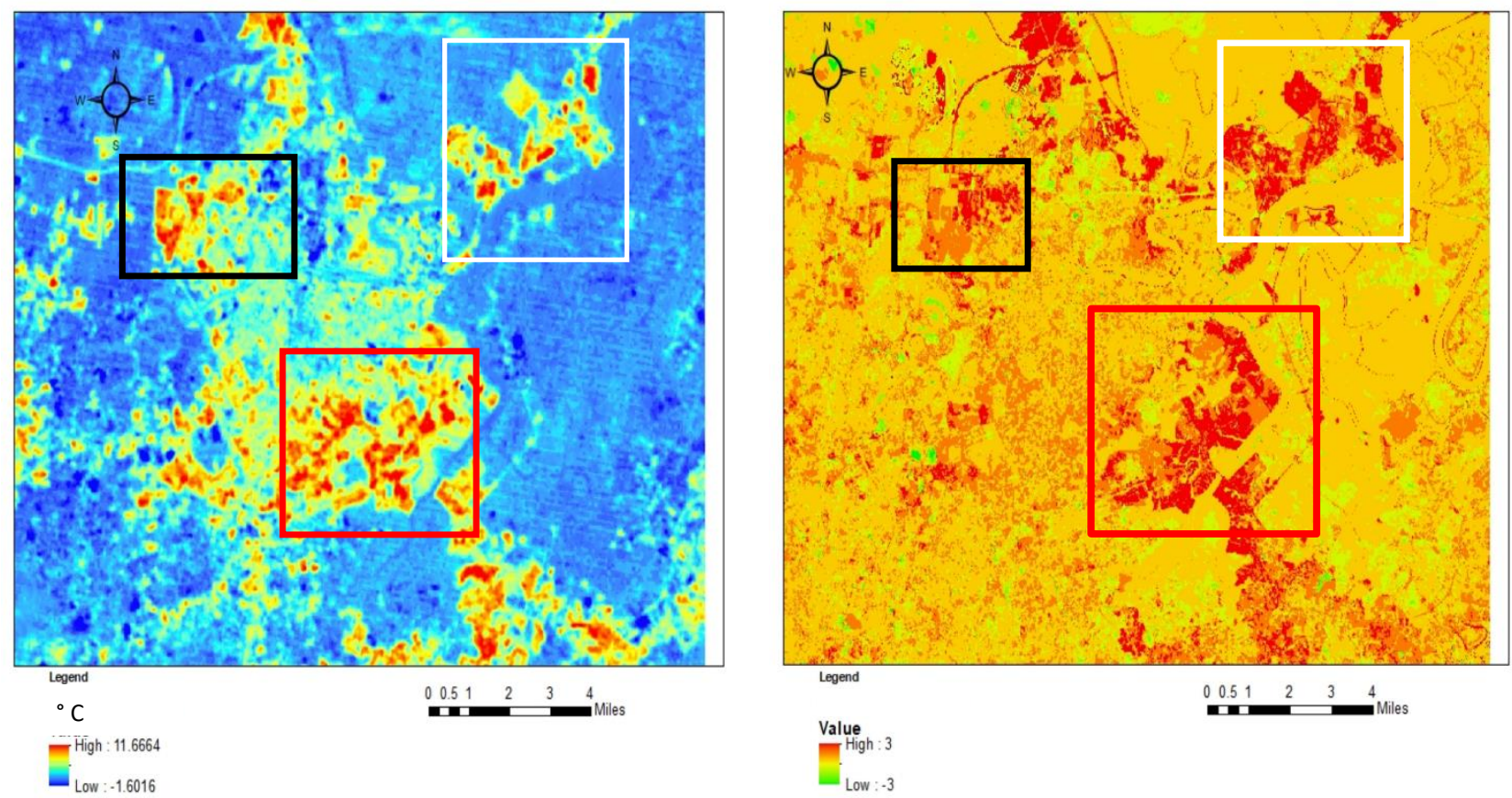

Figure 7 Difference LST between the years 1988 and 2019 (left) and land cover change detection between 1988 and 2019 (right)

Source: Authors

There was a strong negative correlation observed between wetland area $\left(\mathrm{km}^{2}\right)$ with LST with $\mathrm{R}^{2}$ value 0.866 (Figure 8). Figure 8 also shows a strong relationship that the larger the wetland area, the lower the mean LST. This was a vital characteristic of wetland in reducing LST.

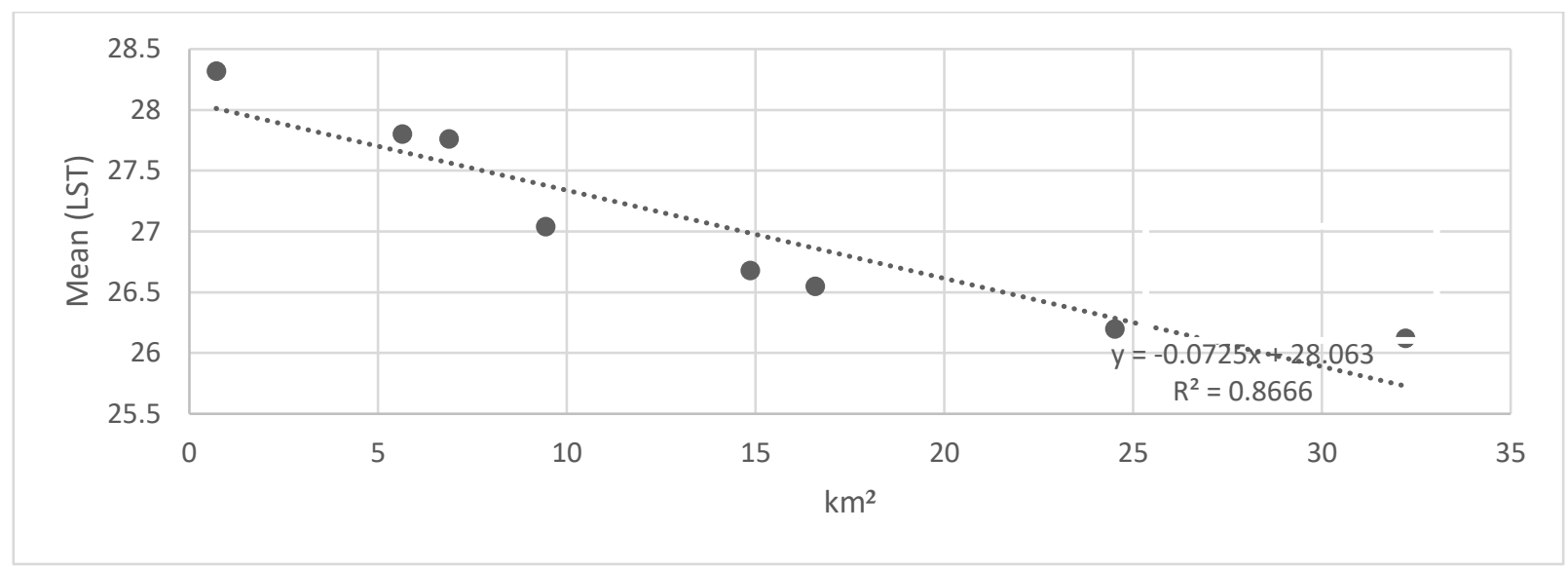

Figure 8 Scatter plot of correlation between wetland area and LST.

Source: Authors.

It was achieved due to the high evapotranspiration released from the wetland that could affect cooling the local climate. From the analysis, it was found that with loss of every five $\mathrm{km}^{2}$ of wetland, the subsequent cooling effect was diminished to result from a hike of $1^{\circ} \mathrm{C}$ of LST.

\subsection{CONCLUSION}

Wetland and vegetation were found to strongly correlate to the local climate. The decrease in the quantity of wetland area and vegetation covers significantly increased the LST. The use of remote sensing here presented a practical way to detect the thermal environment of a wetland and its surrounding area. Besides that, remote sensing technology was demonstrated to the impact of land cover change to LST on a more extensive and local scale. The 
results showed the correlation between the size area of wetland and LST. For every $5 \mathrm{~km}^{2}$ wetland area lost an increase in 1 degree Celsius of LST was estimated. The size area of wetland influenced on LST was significant. Wetland was found as a critical component in the earth's surface in reducing urban heat effects and climate change. The result of this study is proof of the importance of land cover type vegetation and wetland in balancing the energy to create sustainable development in the future at Sarawak. Sustainable development is in important part to achieve the low carbon city to reduce the demand for energy to reduce the effect of urban heat island effect.

\section{Conflict of Interests}

The authors declare that there is no conflict of interest regarding the research works presented in this paper.

\section{Acknowledgment}

Thanks to NASA policy in free access is given to data of Landsat generation.

\section{References}

[1] Board M E A. (2005). Ecosystems and Human Well-Being: Wetlands and Water Synthesis.

[2] Guo, M., Li, J., Sheng, C., Xu, J., Wu, L., (2017). A review of wetland remote sensing. Sensors 17, 777. http://dx.doi.org/10.3390/s17040777.

[3] Díaz-Delgado, R., Aragon, D., Afn, I., Bustamante, J., (2016). Long-term monitoring of the flooding regime and hydroperiod of Do nana marshes with Landsat time series (1974-2014). Remote Sens. 8, 775. http://dx.doi.org/10.3390/rs8090775.

[4] Betbeder, J., Rapinel, S., Cologne, S., Pottier, E., Hubert-Moy, L., (2015). TerraSAR-X dual-pol time-series for mapping of wetland vegetation. ISPRS J. Photogramm. Remote Sens. 107, 90-98. http://dx.doi.org/10.1016/j.isprsjprs.2015.05.001.

[5] Anderson, M.C., Allen, R.G., Morse, A., Kustas, W.P., (2012). Use of Landsat thermal imagery in monitoring evapotranspiration and managing water resources. Remote Sens. Environ. 122, 50-65. http://dx.doi.org/10.1016/j.rse.2011.08.025.

[6] Chen Y. (1999). The trends of global change research in China. Advance in Earth Sciences, 14(4): 319-323. https://doi.org/10.1007/s11769-015-0735-4

[7] Luyssaert, S., Jammet, M., Stoy, P.C., Estel, S., Pongratz, J., Ceschia, E., Churkina, G., Don, A., Erb, K., Ferlicoq, M., Gielen, B., Grunwald, T., Houghton, R.A., Klumpp, K., Knohl, A., Kolb, T., Kuemmerle, T., Laurila, T., Lohila, A., Loustau, D., McGrath, M.J., Meyfroidt, P., Moors, E.J., Naudts, K., Novick, K., Otto, J., Pilegaard, K., Pio, C.A., Rambal, S., Rebmann, C., Ryder, J., Suyker, A.E., Varlagin, A., Wattenbach, M., Dolman, A.J., (2014). Land management and land-cover change have impacts of similar magnitude on surface temperature. Nat. Clim. Change 4, 389-393. http://dx. doi.org/10.1038/nclimate2196

[8] Lofgren, B. M. (1997). Simulated effects of idealized Laurentian Great Lakes on regional and large-scale climate. Journal of Climate, 10(11): 2847-2858. DOI: 10.1175/1520-0442(1997) 010<2847: SEOILG>2.0.CO;2

[9] Chen X.L., Zhao H.M., Li P. X., Yin Z. Y. (2006). Remote sensing image-based analysis of the relationship between urban heat island and land use/cover changes. Remote sensing of environment, 104(2): 133-146. https://doi.org/10.1016/j.rse.2005.11.016

[10] Du, J., Song, K., \& Yan, B. (2019). Impact of the Zhalong Wetland on Neighboring Land Surface Temperature Based on Remote Sensing and GIS. Chinese Geographical Science, 29(5), 798-808.

[11] Song C. (2003). Advance in research on carbon cycling in wetlands. Scientia Geographica Sinica, 23(5): 622-628. https://doi.org/10.13249/j.cnki.sgs.2003.05.622

[12] Nie, X., Wang Y., (2010). 'Cold-humidity Island' effect of marsh wetlands on localized micro-climate. Journal of Ecology and Rural Environment, 26(2): 189-192. https://www.cabdirect.org/cabdirect/abstract/20103144224

[13] Chuan, T., Congsheng, Z. (2006). Review and analysis of carbon cycling and carbon balance model in the wetland's ecosystem. Journal of Subtropical Resources and Environment, 1(3): 84-92.

[14] Caia, Y., Chen, Y., Tong, C. (2019). Spatiotemporal evolution of urban green space and its impact on the urban thermal environment based on remote sensing data: A case study of Fuzhou City, China. Urban Forestry \& Urban Greening, 41(2019) 33-343. http://dx.doi.org/10.1007/s11769-010-0132-y

[15] Yang, J., Sun, J., Ge, Q.S., Li, X.M. (2017). Assessing the impacts of urbanization-associated green space on urban land surface temperature: a case study of Dalian, China. Urban For. Urban Gree. 22, 1-10. https://doi.org/10.1016/j.ufug.2017.01.002.

[16] Yu, Z.W., Guo, X.Y., Zeng, Y.X. (2018). Variations in land surface temperature and cooling efficiency of green space in rapid urbanization: The case of Fuzhou city, China. Urban For. Urban Gree. 29, 113-121. https://doi.org/10.1016//j.ufug.2017. 11.008.

[17] Sa'adi, Z., Shahid, S., Ismail, T., Chung, E.S., and Wang, X.J. (2017). Distributional Changes in Rainfall and River Flow in Sarawak, Malaysia. Asia-Pac. J. Atmos. Sci., 53(4), 489-500. https://doi.org/10.1007/s13143-017-0051-2 
[18] United Nations (UN), (2018). World Urbanization Prospects: The 2018 Revision (In).

[19] Zhou, D, Xiao, J., Bonafoni, S., Berger, C., Deilami, K., Zhou, Z., Frolking, S., Yao, R., Qiao, Z., and Sobrino, J.A. (2019). Satellite Remote Sensing of Surface Urban Heat Islands: Progress, Challenges, and Perspectives. Remote Sens. 2019, 11, 48; https://doi.org/10.3390/rs11010048

[20] Kemarau, R. A., \& Eboy, O. V. (2020). Urbanization and it impacts to land surface temperature on small medium size city for year 1991, 2011 and 2018: Case study Kota Kinabalu. Journal of Borneo Social Transformation Studies, 6(1), 58-76. 